NASA Technical Memorandum 87215

\title{
Application of Intersatellite Links to Domestic Satellite Systems
}

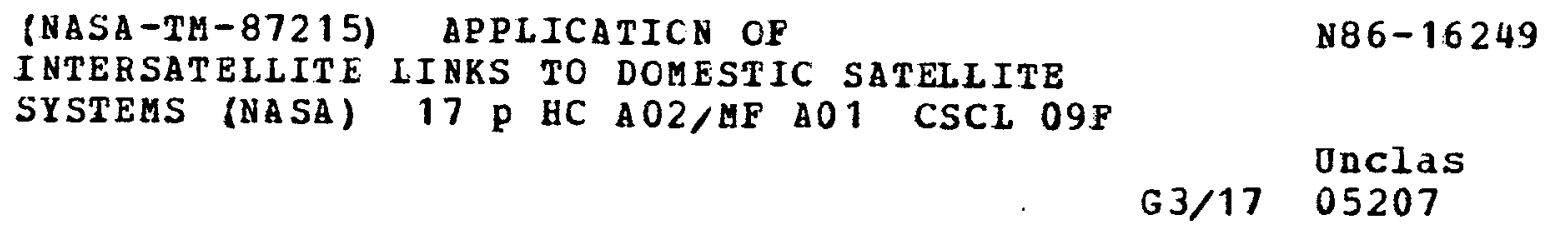

Denise S. Ponchak and Rodney L. Spence

Lewis Research Center

Cleveland, Ohio

Prepared for the

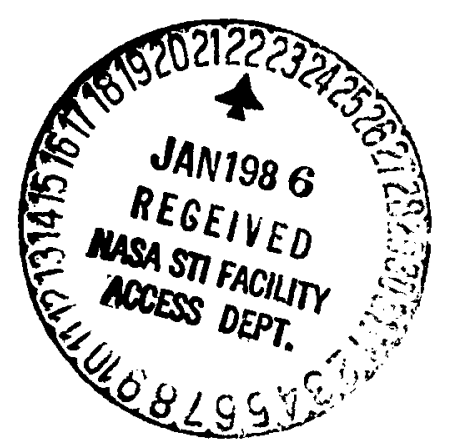

11th Communications Satellite Systems Conference sponsored by the American Institute of Aeronautics and Astronautics San Diego, California, March 16-20, 1986 


\section{APPLICATION OF INTERSATELLITE LINKS TO DOMESTIC SATELLITE SYSTEMS}

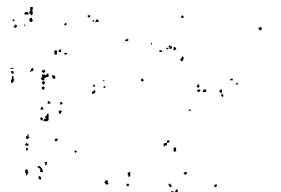

Abstract

This paper presents the results of a study on intersatellite link (ISL) applications. for domestic satellite communications. The objective was to determine if any technical, economic, or performance benefits could be gained by introducing intersatellite links into a domestic satellite communication network. In this study, several key systems issues of domestic ISL's are addressed. These include the effect of a skewed traffic distribution on the selection of ISL satellite orbit locations, tolerable satellite spacing, and crosslink traffic-handling requirements. An ISL technology assessment is made by performing a parametric "link analysis for several microwave and optical implementations. The impact of the crosslink on the end-to-end link performance is investigated for both regenerative and nonregenerative ISL a architectures. Lastly, a comparison is made between single satellite systems operating at $\mathrm{C}-$, and $\mathrm{Ku}-\mathrm{b}$ ands and the corresponding ISL systems in terms of ground segment cost, space segment cost, and net link performance. Results indicate that ISL's can effectively expand the CONUS orbital arc, with a $60 \mathrm{GHz}$ ISL implementation being the most attractive.

\section{$\because \ldots \quad \therefore \quad$ Introduction}

Over the past year, Lewis Research Center has addressed the applicability of Intersatellite Links (ISL's) to U.S. domestic satell ite communications. Although there have been many ISL studies, the majority of them deal with ISL technology without addressing the costs and benefits of ISL systems architectures. In this study we addressed a broad range of ISL issues arising from an initial set of "considerations." These considerations are briefly examined below:

(1) The use of ISL's permits the placement of spacecraft outside the slot locations which provide full cONUS or 48-state coverage. Normally such "outside" locations would allow only partial CONUS coverage. However, by linking such spacecraft to.another satellite in an appropriate position, full CONUS connectivity can be achieved.

(2) Given that spacecraft location impacts ISL throughput requirements, this report quantitatively addresses the following questions:

(a) What are the required ISL capacities as a function of orbit location?

(b) What is the potential impact of skewed ISL traffic (west to east versus east to west) on ISL design?

(c) What amount of orbital arc expansion is "realistic"??

(3) With the prospect of less than full CONUS coverage, single beam spacecraft would have higher gain antennas. This, in turn, would lead to increased spacecraft receive $G / T$ and the potential to decrease HPA output power. The report quantitatively addresses the communications payload weight and power requirements to determine if any margin exists for the addition of 'an ISL.

(4) The addition of an ISL to any domestic systems architecture adds delay and decreases endto-end link performance. The report addresses the following questions:

(a) Are there particular classes of service which cannot tolerate additional delay?

(b) What are the best ways to compensate for decreased link performance? Is baseband processing (BBP) necessary?

(c) How do the current ISL technologies perform against satellite separation and throughput requirements?

(5) Given the above, what are the ISL service costs compared to conventional satellite systems? What are the ISL technology, cost and performance requirements to allow ISL implementation at equivalent service costs?

To address the above considerations, it was necessary to establish some study ground rules. First, only conUS traffic was considered. Secondly, the ISL systems were treated as closed entities competing with conventional U.S. domestic satellite systems. And finally, competition for slot assignments from international or other regional or domestic satellite systems was ignored.

The main text of this report is organized into the following study areas:

A. General ISL Systems Considerations

B. ISL Technology Assessment

C. Impact of Crosslink on End-to-End Performance

D. Spacecraft System Cost Comparison

E. Summary of Conclusions

\section{A. ISL Systems Considerations}

In this section, the use of an ISL to alleviate congestion of prime locations in the geostationary orbit is examined assuming a simple 2-satellite ISL configuration, shown in Fig. 1 . Service is provided to coNUS through the ISL network composed of two single-beam spacecraft supplying aggregate coverage. This allows placement of spacecraft outside the normal visible arc. 


\section{Satellite Visibility}

The conus orbital arc is defined to be the region of orbital slots from which a satellite can provide coverage to all locations in CONUS at elevation angles exceeding a specified minimum."The minimum elevation angle required for each frequency band was chosen to limit the amount of rain attenuation incurred by a signa 1 as it travels through the atmosphere. The angles were chosen to be $5^{\circ}, 10^{\circ}$, and $30^{\circ}$ for $\mathrm{C}, \mathrm{Ku}$, and $\mathrm{Ka}$-band respectively.

In determining the CONUS orbital arc corresponding to each frequency band, two reference point locations were selected to define the eastern and western bounds of CONUS. They were Augusta, Maine $\left(44.25^{\circ} \mathrm{N} / 69.75^{\circ} \mathrm{W}\right)$ and Seattle, Washington $\left(47.60^{\circ} \mathrm{N} / 123.40^{\circ} \mathrm{N}\right)$. Using these locations and the appropriate minimum elevation angle criteria, the ConUS orbital arcs for $\mathrm{C}, \mathrm{Ku}$, and $\mathrm{Ka}-\mathrm{b}$ and were computed to be:

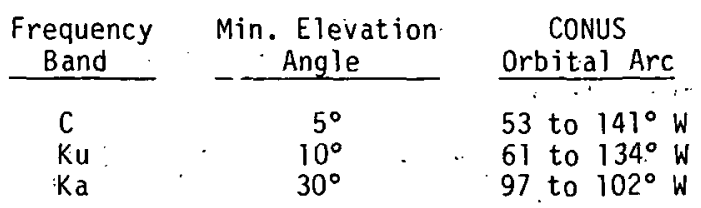

\section{Traffic Considerations}

The distribution of satellite addressable traffic plays a major role in determining prime orbit locations for ISL satellites. Major metropolitan areas have very lárge traffic volumes compared to rural areas. This results in a highly skewed traffic distribution for CONUS, with heavy traffic concentration on the east..and west coasts where large:population densities exist. As a satellite is moved beyond the limits of the CONUS orbital arc, the amount of traffic it can address decreases as a result of its diminishing coverage area. Using a 45-node- in-house traffic-distribution model, the estimate of addressable traffic based on the satellite longitude was determined and is shown on Figs. 2, 4, and 6 for $C, K u$, and $\mathrm{Ka-band}$, respectively. Some of this traffic will be intra-regional and remain in the satellite's main beam, the rest requires an ISL to reach-itsdestination. Results of a downlink/crosslink traffic routing analys is are shown in Figs. 3, 5, and 7 for $\mathrm{C}, \mathrm{Ku}$, and $\mathrm{Ka}-\mathrm{b}$ and respectively. Also shown on these graphs is the 50 percent geographic coverage limit. Within this range of slots, a satellite can provide coverage to at least half of CONUS.

Examination of Figs. 2 through 7 reveals two important system design considerations. First, for a balanced traffic load between two spacecraft using an ISL interconnect, area coverage differs between the east and west spacecraft. This, in turn, implies differing spacecraft antenna gain and G/T characteristics. Thus, an "ISL system" may be designed for specific orbit. locations and require unique earth terminal design depending upon which spacecraft is to be accessed. Second, and conversely, forcing equal spacecraft coverage areas to gain advantages in uniform design of both spacecraft and earth terminals results in an asymmetric ISL crosslink design. By inspection of Figs. 3,5 , and 7 , we conclude that the "west to: east" crosslink is likely to require more capacity than the return link.

Additionaliy, crosslink capacity requirements can be approximated using Figs. 3, 5, and 7. A conventional $C$-band CONUS coverage spacecraft will use dual polarization to achieve a gross capacity of twenty-four 60 Mbps transponders. For easterly orbit slot assignments, the ISL capacity (Fig. 3) grows slowly until the 50 percent level is reached. Assuming a fully loaded satellite, the approximate ISL capacity at $14^{\circ} \mathrm{W}$ is $720 \mathrm{Mbps}$ (twe, lve 60 Mbps transponders). An equivalent. spacecraft-displacement to the west $\left(39^{\circ}\right)$ results in an orbit slot..at $180^{\circ}$ (east or west) and a net crosslink capacity of 85 percent of full capacity or approximately 1.2 Gbps (twenty 60 Mbps transponders). We would suspect that designs requiring the vast majority of traffic to use the crosslink would likely be rejected by system planners as inefficient. Thus, it appears that crosslinks for $\mathrm{C}$ and $\mathrm{Ku}$-band systems would not likely exceed approximately 1.0 Gbps. By simplé bandwidth ratios, crosslinks at $\mathrm{Ka}-\mathrm{b}$ and are not likely to exceed 3 to 4 Gbps.

In addition to capacity, satellite separation is an important ISL design parameter. We find from Fig. 3 that the maximum orbital separation between two ISL satellites maintaining full CONUS coverage is $140^{\circ}$ for $\mathrm{C}$-band. Figures 5 and 7 show that Ku-band has a maximum separation of $125^{\circ}$ while Ka-band has a $58^{\circ}$ separation limit. Satellite separations. exceeding these values will. not permit full conUS coverage between the two. spacecraft.

Based on the above discussions if we restrict ISL capacity to no more than 70 percent of total spacecraft capacity, since it is unlikely that this value would be exceeded in a real system, then the potential increase in orbital arc for $C$, $\mathrm{Ku}$ and $\mathrm{Ka}$-band, respectively, are 71 percent (slots from 8 to $162^{\circ} \mathrm{W}$ ), 97 percent (slots from 14 to $158^{\circ} \mathrm{W}$ ), and 1433 percent (slots from 39 to $\left.130^{\circ} \mathrm{W}\right)$. These figures were calculated assuming that the orbital spacing for $\mathrm{C}$ and Ku-band sat-. ellites would remain at $2^{\circ}$ while the Ka-band satellites would be located at $1^{\circ}$ intervals. We conclude that ISL's enable dramatic increases in orbital arc utilization for the higher frequency. bands :

\section{ISL Delay. Impact}

The traffic distribution model used up to this point represents total long-haul communications traffic that is addressable by satellite. The total traffic can be divided into three service categories. The first and largest service is for voice communications, accounting for approximately 77 percent of the total traffic. The second is data services which accounts for 8 percent of the total. The remaining 15 percent of the total traffic is comprised of video services.

In a system that employs intersatellite links, the transmitted signal will. be subjected to an additional time delay proportional to the satellite spacing. The CCITT recommends as a network performance objective that the mean oneway transmission delay not exceed $400 \mathrm{msec}$ for voice circuits. This is provided that echo 
suppressors and cancellers are used. Of this $400 \mathrm{msec}$, approximately $290 \mathrm{msec}$ is used by the up and downlinks and the terrestrial extensions. This leaves $110 \mathrm{msec}$ delay for the ISL which will allow a maximum satellite separation of $50^{\circ}$, which for $\mathrm{C}$ and Ku-band prohibits the placement of both ISL satellites outside of the CONUS orbital arc.

Data systems normally employ a form of automatic repeat request error correction (ARQ), either stop and wait ARQ or continuous ARQ, the former being most commonly used. After a block of data is sent, the transmitter must pause and wait for an acknowledgment signal before any further transmissions occur. If the acknowledgment is positive (no errors), the next block of data is sent; if it is negative (errors), the same block of data is retransmitted. When the path lengths, and subsequently path delays, increase, the link throughput is decreased thus lowering transmission efficiency. Continuous ARQ is more immune to transmission delays. With this protocol, the transmitter continually sends data blocks and receives back a steady stream of acknowledgment signals. The system requires sufficient storage to hold the data until an acknowledgment is received in case the data must be retransmitted. The amount of storage required depends on the bit-rate and the length of the round-trip delay. The incremental amount of buffering needed with an ISL satellite system over conventional satellite systems would be proportional to the increase in the transmission delay.

The additional propagation delay of the intersatellite link can severely limit the amount of voice and data traffic that the system can capture. Voice traffic requirements restrain the satellite separation to $50^{\circ}$. The length of the delay increases the amount of storage needed for data transmission, or lowers the efficiency. Propagation delay has no significant effect on television transmission and other one-way services.

\section{B. ISL Technology Assessment}

In order to assess the suitability of millimeter wave (MMW) and optical systems for use in intersatellite links, a parametric analysis involving the basic system variables (antenna or optic size, transmit power, data rate, etc.), was performed under certain system assumptions. Then a comparison of the various ISL types was made on a weight, prime power, and performance basis.

\section{Selection of RF and Laser Systems}

For MMW systems, crosslink frequencies in the 23,32 , and $60 \mathrm{GHz}$ bands were studied for which the allocated bandwidths are 1, 1, and $5 \mathrm{GHz}$, respectively. Higher microwave frequencies were not considered because of the lack of component technology in these bands. Among the available laser sources are the FD Nd:YAG, HeNe, $\mathrm{GaAs}$, and $\mathrm{CO}_{2}$ lasers. Characteristics of these principal laser sources are shown in Table 1. The FD Nd:YAG diode pumped laser and the GaAs semiconductor laser were chosen to be best suited for ISL application primarily because these approaches are amenable to simple and efficient direct-detection techniques. Thus, the receiver is essentially a power detector or "photon bucket" and the phase of the received signal is unimportant. This is in contrast to the $\mathrm{CO}_{2}$ gas laser system which requires heterodyne detection and hence highly stable transmitters, an additional laser at the receiver for the local oscillator, as well as precise tracking of the received optical wavefront and polarization. Further, the $\mathrm{CO}_{2}$ laser requires cryogenically cooled detectors to suppress internal noise and its present lifetime is not sufficient for space qualification. Other reasons why the YAG diode-pumped laser and GaAs laser are the preferred optical ISL system approaches are long lifetime and reliability, production of modest output power, and availability of wide-band traveling wave electrooptic modulators and high-gain low-noise photodetectors. It should also be mentioned that the other common laser source, the HeNe laser, while being the most mature of laser sources with a very high reliability, is severely limited in output power and efficiency; therefore the HeNe laser should probably be considered only for very short-range or intra-cluster ISL applications.

\section{System Parameters and Requirements}

A summary of some of the basic ISL system parameters and requirements used in the analys is is given below. Values of transmit power represent current or near-term state of the art.

(1) Frequency: 23, 32, $60 \mathrm{GHz}$ and FD. Nd:YAG $(0.53 \mu \mathrm{m})$, GaAs $(0.83 \mathrm{~m})$

(2) Satellite spacings: $30^{\circ}$ to $140^{\circ}$ (maximum separation for line-of-sight view is $163^{\circ}$ )

(3) BER: $10^{-7}$

(4) Data rate: 1 Gbps crosslink

(5) Modulation: uncoded QPSK - MMW systems; continuous optical carrier intensity modulation, direct detection - lasers

(6) Antenna/optics diameters: 3, 4, and $5 \mathrm{ft}$ parabolic reflectors - MMW; 6,12 , and 24 in. optics apertures - laser (same size antennas assumed on both ends of crosslink)

(7) Maximum transmit power: $75 \mathrm{~W}-\mathrm{MMW}$, $100 \mathrm{~mW}$ - GaAs, $500 \mathrm{~mW}$ - FD Nd:YAG

(8) Noise source: $1500 \mathrm{~K}$ receiver noise temp - MMW; $4 \times 10^{-10} \mathrm{~W}$ background solar radiation noise - laser (sun modeled as a blackbody radiator at $\mathrm{T}=6000^{\circ} \mathrm{K}$ )

\section{ISL Systems}

In order to make a comparison of the different ISL technologies in terms of performance capability, prime power required, and weight burden on the satellite, the following approach was used: (1) curves relating the required crosslink EIRP for a nominal crosslink bit-error-rate (BER) of $10^{-9}$ were generated as a function of satellite longitudinal separation for parametric values of data rate and antenna/optics diameter for each of the ISL types, (2) average RF and laser output power values necessary to produce the above EIRP's were determined, (3) weight and 
power models (MMW model was developed in-house, while the laser model was developed by COMSAT) using the above parameters as inputs were applied to the MMW and optical systems to obtain estimates of the ISL subsystem weight and prime power. From these data, curves relating ISL weight and prime power to transmitting EIRP were generated, and (4) a comparison was made among the various ISL types, cognizant of the state of art (SOA) technological constraints applying to each, to determine which approach offered the least weight and power burden on the spacecraft for the given data rate crosslink operating over a range of satellite angular spacings.

The results of the analysis procedure are shown in Table 2, listing each of the ISL systems along with their corresponding variation in required EIRP, transmit RF or laser power, prime power, and subsystem weight as the satellite separation is increased from $30^{\circ}$ to $140^{\circ}$. In examining the table, the following comments apply:

(1) Among lasers, systems using smaller diameter optics weigh less than ones using larger diameters since most of the ISL mass is concentrated in the acquisition and tracking subsystem ( 40 to 70 percent of total weight) where submicroradian tracking and pointing accuracy is required. As an example of the extremely narrow optical beams and formidable pointing problems invoived, an ISL system using a FD Nd:YAG laser with 6 in. optics will transmit a beamwidth of about $4.2 \mu \mathrm{rad}$. Therefore, to constrain transmit and receive pointing losses to less than $3 \mathrm{~dB}$, a pointing accuracy of 2.1 urad is necessary, roughly the angle subtended by a dime from a distance of 5 miles. The majority of prime power is also absorbed in the acquisition/tracking and optical modulation subsystems rather than as input to the laser itself. Thus, at a given data rate and optics diameter. ISL subsystem weight and prime power are relatively insensitive to laser output power and angular separation.

(2) Unlike the optical systems, MMW ISL's exhibit a high dependency of prime power and weight on EIRP and longitudinal separation. This is because TWTA output power is the major factor driving the prime power requirement and resultant transponder and power subsystem weights. Therefore, in contrast to optical systems, it is more advantageous to use larger diameter antennas and reduce the $r f$ output power requirement to a minimum.

(3) The $60 \mathrm{GHz}$ ISL implementation using $5 \mathrm{ft}$ reflectors offers significant weight and power advantages over the other methods. From Table 2, this package weighing about $35 \mathrm{Kg}$ (77 1b) and consuming $70 \mathrm{~W}$ of prime power can sustain a 1 Gbps data rate link at a BER of $10^{-7}$ or better out to $140^{\circ}$ separation. This implementation is 15 to $25 \mathrm{~kg}$ lighter than the 6 in. laser systems. It should be noted, however, that COMSAT characterized their optical ISL weight and power model as being very conservative.

A closer look at these implementations is shown in Fig. 8. Here the data rate has been extended out to 4 Gbps and ISL package weight is plotted as a function of satellite separation for a crosslink BER of $10^{-7}$. We see that for the same data rate, $60 \mathrm{GHz}$ systems are always lighter than laser systems. Laser ISL's, however, exhibit apparent advantages over RF systems in certain operating regimes. For data rates greater than 1 Gbps, the laser systems can more easily achieve high Eb/No. within SOA power levels. Note also that lasers have an important advantage over RF systems at the higher data rates in that their weight is for the most part distance insensitive. Therefore for a given data rate and performance requirement, an ISL laser package will weigh approximately the same regardless of crossink separation.

In contrast, RF ISL subsystem weight is highly dependent on satellite spacing at high data rates (especially 4 Gbps and higher) so that a major driver of the ISL package design would be the projected ISL separation distance. As data rates decrease, however, $60 \mathrm{GHz}$ ISL weight becomes more distance insensitive and the technology offers reduced weight and power penalty on the satellite, near-term availability of components, and simplicity of design. Also, in comparison to other MMW systems, $60 \mathrm{GHz}$ offers the advantage of reduced antenna size and TWT power, and larger available bandwidth as well as avoiding the potential RFI problem that the 23 and $32 \mathrm{GHz}$ bands may encounter.

From the models, laser and RF technology needs can be identified. For RF systems, higher power, higher efficiency transmitters are necessary for large separation, high data rate applications. For laser systems, reduced mass acquisition and tracking systems and reduced power consumption for the laser modulator system are necessary for similar applications.

\section{Impact of Crosslink on End-to-End Link Performance}

With the insertion of a crosslink into a 2-satellite ISL configuration, overall link performance is degraded, with the weakest of the three segments (uplink, crosslink, or downlink) determining end-to-end $B E R$, assuming conventional translating repeaters. Reasonable BER objectives are dependent on the type of service being offered; generally BER's in the range of $10^{-3}$ to $10^{-4}$ are considered acceptable for digitized voice data while BER's in the range of $10^{-6}$ to $10^{-7}$ are considered satisfactory for digital video and data signals.

In our study of domestic ISL's, the impact of crosslink insertion was measured by comparing the BER performance of a typical C-band and $\mathrm{Ku}$-band single satellite system, providing single-beam CONUS coverage, to that of their ISL counterparts in which each satellite of the 2 -satellite ISL system provides single beam coverage to half the CONUS area. In making this comparison it was noted that: (1) crosslink degradation is partially offset by an improved uplink G/T resulting from the use of a larger antenna to provide the reduced amount of satellite coverage, and (2) the larger antenna allows the reduction of downlink HPA power while maintaining the same net EIRP. This combination translates into a net weight savings which can then be reallocated to the ISL subsystem.

It should be emphasized that the crosslink degradation results presented in this section are 
entirely specific to the link budget characteristics that were chosen for these systems. U1timately, the effect on overall performance of introducing the ISL will depend on the relative values of uplink, crosslink, and downlink $\mathrm{Eb} /$ No, the coding technique used, as well as whether IF or baseband processing is employed on the satellite. One can imagine an ISL scenario in which the crosslink Eb/No is significantly greater than the uplink or downlink Eb/No so that, performancewise, it is essentially "transparent" to the system except for the added propagation delay. However, such large crosslink Eb/No requirements lead to large output power levels. To illustrate this, Fig. 9 is a plot of the received crosslink $\mathrm{Eb} / \mathrm{No}$ and the corresponding $\mathrm{BER}$ as a function of satellite spacing for a $60 \mathrm{GHz}, 1$ Gbps link using 5-ft transmit and receive reflectors and a laser link using 6 in. optics. The separate curves correspond to different values of RF and laser output power.

From the figure, we see that more than $130 \mathrm{~W}$ of RF power at $60 \mathrm{GHz}$ is necessary to maintain a crosslink $E b^{\prime} /$ No of at least $20 \mathrm{~dB}$ out to $140^{\circ}$ separation. This is currently beyond the capability of conventional helix-type TWT's. For the laser, the required power level is about $400 \mathrm{~mW}$, which is within the SOA. By going to $12 \mathrm{in.}$ optics, this power is reduced to an easily achieved value of $25 \mathrm{~mW}$. Thus, in designing transparent ISL's for wide angular spacings, optical links appear more suitable than MMW given the current state of technology.

It should also be mentioned that if the crosslink was effectively made independent from the uplink and downlink through the use of IF or BBP at both its transmitting and receiving ends, then "transparency" can be much more easily achieved since the overall BER is now the sum of the individual link segment BER's. For example, from Fig. 9, $10^{-10}$ BER can be obtained on the crosslink, at $140^{\circ}$ spacing, using approximately $50 \mathrm{~W}$ and $100 \mathrm{~mW}$ for the $60 \mathrm{GHz}$ and laser systems, respectively.

Representative link budgets for the $\mathrm{C}$-band and $\mathrm{Ku}-\mathrm{b}$ and single-beam CONUS coverage systems are shown in Tables 3 and 4. Major system parameters are typical of those from the Ku-band SBS system and C-band RCA Satcom system. Slight differences exist, however, due to the elliptici.ty of the spacecraft antenna. A comparison of the end-to-end link performance between the single satellite baseline and ISL configurations is shown in Table 5 for both $\mathrm{C}$-band and Ku-band. Indicated on the table is the net Eb/No values and the BER's they produce for coding/noncoding modes of operation. Also shown for the ISL cases is the BER performance of the system with IF demodulation/ remodulation on the satellites at the point where the crosslink interfaces with the downlink. In this type of processing, the received crosslink signal is frequency translated to IF and the entire IF signal is remodulated onto the downlink carrier. By this method, the accumulated noise on the uplink and crosslink is isolated from the downlink, which is normally the weakest link in the chain. Overall BER is then the sum of the BER's on each of the two isolated segments (uplink/crosslink + downlink). The obvious penalty in this approach is the necessity for additional downlink bandwidth when compared to uplink bandwidth. For this reason, such a system is unlikely to find application at $C$ or Ku-band, but may offer some appeal for certain applications at Ka-band where a large bandwidth allocation exists.

By examination of Table 5, the following observations can be made:

(1) If the single satellite system is designed for a BER performance acceptable for voice, then it appears that the insertion of the crosslink has no appreciable impact in moving the BER performance out of the acceptable range. Related to this point is the fact that propagation delay factors for voice will generally constrain ISL spacings to less than about $50^{\circ}$ in which case present or near-term technology permits a much higher quality crosslink (Fig. 9) than the $11.3 \mathrm{~dB} \mathrm{~Eb} /$ No $\left(10^{-7} \mathrm{BER}\right)$ link assumed here.

(2) If the single satellite system is designed for a BER performance acceptable for data and video traffic $\left(10^{-6}\right.$ to $10^{-7}$ range requires $R=7 / 8$ code for $C$-band, $R=3 / 4$ code for $K u-b a n d)$, then the resulting BER's after crosslink insertion are still satisfactory.

(3) For the satellite configurations studied here, the use of demodulating/ remodulating transponders for the ISL is unnecessary unless one desires an improvement in performance over the single satellite system.

As mentioned before, the selection of uplink-cross link-down Tink design parameters, coding scheme, modulation format, etc., are made to conform to a particular system appiication and its requirements. The primary purpose for analyzing these particular configurations was to demonstrate quantitatively what the impact of an ISL can be, how it relates to the present SOA, and where compromises can occur.

\section{Spacecraft Weight and Cost Estimates}

The next stage in studying the feasibility of ISL systems was to determine if any payload weight margins would result from the trade-off of reduced downlink HPA power for increased antenna gain, which could accommodate an ISL package without increasing the overall satellite weight. The satellite payload was defined to consist of the transponder subsystem, the antenna subsystem, and the portion of the power subsystem dedicated to the transponders. The ISL package was treated as a separate entity from the communications payload though it is recognized that the two will be interconnected.

Using in-house payload weight algorithms, the communications payload weight of the ISL satellite was calculated and compared to that of a baseline CONUS satellite having equal downlink performance. The design of the payloads were identical except for the transmitting power and the antenna size (obtained from Tables 3 and 4 ). The increased antenna size of the ISL satellite produces a weight penalty, whereas the reduced transmit power lowers the weight and operating power requirements. A payload comparison for both $\mathrm{C}$ and $\mathrm{Ku}$-band is shown in Table 6 . As can be seen from these results, ISL weight margins 
were achieved for both frequency bands. Referring to Fig. 8, we see that a $751 \mathrm{~b}$ ISL weight margin for a C-band ISL satellite corresponds to the estimated weight of a $60 \mathrm{GHz}$ package consisting of a 5-ft antenna and a 25-W TWTA. Implementing this package has the capability of offering a 1 Gbps capacity crosslink at $10^{-7}$ BER for separations as large as $140^{\circ}$. For medium-range separations compatible with voice transmission $\left(40^{\circ}\right.$ to $\left.60^{\circ}\right)$, this package would provide very high quality crosslinks (Eb/No in the 17-20 dB range) with BER's better than $10^{-10}$. This margin would have to be slightly greater in order to accomodate a laser package (weighing approximately 85 lb) although the laser ISL weight model is considered conservative. Also, from Fig. 8 we observe that a 279 lb ISL weight margin for a Ku-band ISL satellite will easily allow implementation of either a laser or microwave ISL package providing crosslink capacities in excess of 4 Gbps over all angular separations.

The final stage was to determine if any economic bënefits could be gained in using ISL's for domestic satellite communications. The approach that was taken was to compare two ISL satellite scenarios to a baseline system. The first ISL scenario was one in which full advantage of the increased antenna gain was taken into account on-board the satellite to provide a weight/cost margin for the ISL package. For this scenario, it was assumed the earth stations would have the same design as the baseline scenario. The second. ISL scenario used the increased antenna gain to provide a cost-reduction of the earth stations through reduced earth station antenna gain and transmitting power. This cost savings could then be used to provide for the larger satellite antenna and ISL package. The baseline scenario consisted of two CONUS satellites so that each scenario provided the same capacity.

The spacecraft cost model (launch cost included) used for this study was an in-house model based on the satellite beginning-of-life (BOL) weight and end-of-life (EOL) power which were determined by a statistical approach based on the payload weight and power requirements. - The earth terminals for the various scenarios were compared by the cost of their RF equipment (antenna, HPA, and LNA). Once again, in-house models were utilized to determine the costs based on the following RF system parameters: antenna diameter, HPA RF power, and system noise temperature. Given the required earth station EIRP and $G / T$ (obtained from Tables 3 and 4 ), these three parameters were determined so as to minimize the RF equipment cost. The earth station characteristics are given in Table 7. All cost values are given in 1984 dollars.

The results given in Table 8 indicate that the first ISL scenario in which the increased antenna gain is advantageously used on-board the spacecraft provides a direct cost margin that could be applied toward the two required ISL packages. The concept of the second ISL scenario does not provide such a direct margin. For this case, many earth terminals would be needed to support the larger satelitite antennas and ISL packages. Even though the exact cost of an ISL package is unknown, it can be seen that this scenario would not be comparable to the baseline scenario unless an unrealistically high number of earth terminals were required.

\section{E. Conclusion}

ISL's have the capability of relieving orbital arc congestion by allowing satellites to be placed outside the normal visible arc with reduced coverage area requirements per spacecraft. For moderately high data rates (up to approximately $2 \mathrm{Gbps}$ ), a $60 \mathrm{GHz}$ MMW implementation seems to currently be the most attractive of the various ISL approaches. Compared to lasers, $60 \mathrm{GHz}$ has a more mature technology base, is simpler in design, has reduced weight and power penalty on the satellite, and avoids the acquisition and tracking problems associated with microradian beamwidth optical systems. However, for multi-gigabit rate, long-range applications exceeding the current capability of MMW SOA, laser systems seem to be more appropriate. In comparison with the $23 \mathrm{GHz}$ and $32 \mathrm{GHz}$ implementations, $60 \mathrm{GHz}$ has the advantage of reduced TWTA power, reasonable antenna size, larger available bandwidth, and immunity to RFI. A $60 \mathrm{GHz}$ ISL using a modest $25 \mathrm{~W}$ of RF power and $5 \mathrm{ft}$ reflectors is capable of supporting a 1 Gbps crosslink at $10^{-7}$ BER for a $140^{\circ}$ satellite separation. This maximum separation corresponds to each satellite covering half the CONUS area at $5^{\circ}$ elevation angle minimum for $C$-band. At separations less than $100^{\circ}$, BER performance exceeds $10^{-10}$ so that for most ISL applications (especially voice service), crosslink degradation on end-toend performance is negligible.

For the $\mathrm{C}$ and $\mathrm{Ku}$-band single beam cases examined, it has been demonstrated that improvements in uplink and downlink performance can be translated into weight and power margins to compensate for ISL weight and power penalties. In this way, a two-satellite system connected by an ISL provides a nearly equivalent or perhaps somewhat superior capability over a simple unconnected two-satellite single-beam system (consider the increased connectivity from a single earth station). However, such advantages are not nearly as evident for multibeam satellite systems. For these satellites, there is no inherent advantage in less than coNUS coverage. Size, weight, and power savings are the direct result of decreased coverage and the resultant decrease in traffic. In order to maintain the same net traffic as the single CONUS multibeam satellite, two smaller multibeam satellites are required, each equipped with an ISL package. Thus, a net increase in service costs is expected.

In improving uplink and downlink performance over single satellite systems, ISL's have their greatest advantage at Ka-band where the ability to place satellites over locations experiencing high rainfall (normally outside the Ka-band CONUS arc) allows a 2 to $4 \mathrm{~dB}$ reduction in rain fade. As far as economic advantages are concerned, a realistic comparison involves making assumptions on the ISL and single satellite systems being studied. In the satellite configurations considered in this report, ISL system costs were not derived as such. Rather, a cost comparison was made between two CONUS satellites and two satellites operating with an ISL (equal capacities) to determine the cost margin that can be allocated 
to the ISL system. For the $\mathrm{C}$ and $\mathrm{Ku}$-band systems, these margins were $\$ 23$ and $\$ 82 \mathrm{M}$, respectively.

\section{References}

1. Gagliardi, R.M., Satellite Communications, Lifetime Learning Publications, 1984.

2. Sivo, J.N., "Advanced Communication Satellite Systems," Microwave Journal; Vol. 27, No. 1, Jan., 1984, pp. 77-95. (ा1 pp.).

3. Stevenson, S., Poley, W., Lekan, J., and Salzman, J.A., "Demand for Satellite-Provided Domestic Communications Services to the Year 2000," NASA TM-86894, 1984.
4. "The Effects of Transmission Delay in the Fixed Satellite Service," Report 383-4, Recommendations and Report of the CCIR 1982, Vol. IV, Part I - Fixed Satellite Service, International Telecommunication Union, Geneva, Switzerland, 1982, pp. 29-36.

5. Welti, G.R. and Lee, Y.S., "Planning Assistance for the $30 / 20 \mathrm{GHz}$ Program, Task 6 Final Report, Study of Intersatellite Links," COMSAT-TASK 123-6031, COMSAT Laboratories. Clarksburg, MD, Nov. 1981. (Also NASA Report $1-11-(-1-T 6)$ 
TABLE 1. - CHARACTERISTICS OF LASER SYSTEMS

\begin{tabular}{|c|c|c|c|c|}
\hline Laser & $\begin{array}{c}\text { Waivelength, } \\
\mu \mathrm{m}\end{array}$ & $\begin{array}{l}\text { Average power } \\
\text { output, } \mathrm{mw}\end{array}$ & $\begin{array}{l}\text { Transmitter } \\
\text { efficiency }\end{array}$ & $\begin{array}{c}\text { Lifetime, } \\
\mathrm{hr}\end{array}$ \\
\hline $\begin{array}{l}\text { FD Nd:YAG } \\
\text { HeNe } \\
\text { GaAs } \\
\mathrm{CO}_{2}\end{array}$ & $\begin{array}{c}0.53 \\
0.63 \\
0.83 \\
10.6\end{array}$ & $\begin{aligned} 100 \text { to } 500 \\
2 \text { to } 5 \\
20 \text { to } 100 \\
1000 \text { to } 2000\end{aligned}$ & $\begin{array}{r}0.5 \text { to } 2 \text { percent } \\
1 \text { percent } \\
5 \text { to } 10 \text { percent } \\
10 \text { to } 15 \text { percent }\end{array}$ & $\begin{array}{ccc}50 & 000 \\
75 & 000 \\
& 50 & 000 \\
5 & 000 \text { to } 10 & 000\end{array}$ \\
\hline
\end{tabular}

TABLE 2. - PRIME POWER REQUIREMENT AND WEIGHT RANGES OF ISL SYSTEMS FOR $30^{\circ}$ TO $140^{\circ}$ SPACINGS (1 GDPS LINK)

\begin{tabular}{|c|c|c|c|c|c|}
\hline System & Diameter & $\begin{array}{l}\text { Required } \\
\text { EIRP (dBW). } \\
10^{-7} \text { BER }\end{array}$ & Transmit power & $\begin{array}{c}\text { Prime power, } \\
W\end{array}$ & $\begin{array}{l}\text { Weight, } \\
\mathrm{kg}\end{array}$ \\
\hline Laser ( $F D$ Nd:YAG) & $\begin{array}{r}6 \text { inch } \\
12 \text { inch } \\
24 \text { inch }\end{array}$ & $\begin{array}{l}94 \text { to } 105 \\
88 \text { to } 99 \\
82 \text { to } 93\end{array}$ & $\begin{array}{l}4 \text { to } 55 \mathrm{mw} \\
0.3 \text { to } 3.5 \mathrm{mw} \\
.02 \text { to } .22 \mathrm{mw}\end{array}$ & $\begin{array}{l}80 \text { to } 95 \\
85 \text { to } 86 \\
90\end{array}$ & $\begin{array}{l}47 \text { to } 50 \\
68 \\
180\end{array}$ \\
\hline Laser (GaAs) & $\begin{array}{r}6 \text { inch } \\
12 \text { inch } \\
24 \text { inch }\end{array}$ & $\begin{array}{l}94 \text { to } 105 \\
88 \text { to } 99 \\
82 \text { to } 93\end{array}$ & $\begin{array}{l}11 \text { to } 136 \mathrm{~mW} \\
.7 \text { to } 8.5 \mathrm{~mW} \\
.04 \text { to } .5 \mathrm{~mW}\end{array}$ & $\begin{array}{l}80 \text { to } 90 \\
85 \text { to } 86 \\
90 .\end{array}$ & $\begin{array}{c}47 \text { to } 50 \\
68 \\
180\end{array}$ \\
\hline $23 \mathrm{GHz}$ & $\begin{array}{l}3 \mathrm{ft} \\
4 \mathrm{ft} \\
5 \mathrm{ft}\end{array}$ & $\begin{array}{l}66 \text { to } 77 \\
63 \text { to } 74 \\
61 \text { to } 72\end{array}$ & $\begin{array}{l}117 \text { to } 1476 \mathrm{~W} \\
33 \text { to } 416 \mathrm{~W} \\
13 \text { to } 168 \mathrm{~W}\end{array}$ & $\begin{array}{l}300 \text { to } 3700 \\
90 \text { to } 1000 \\
40 \text { to } 400\end{array}$ & $\begin{array}{l}76 \text { to } 660 \\
35 \text { to } 220 \\
28 \text { to } 100\end{array}$ \\
\hline $32 \mathrm{GHZ}$ & $\begin{array}{l}3 \mathrm{ft} \\
4 \mathrm{ft} \\
5 \mathrm{ft}\end{array}$ & $\begin{array}{l}66 \text { to } 77 \\
63 \text { to } 74 \\
61 \text { to } 72\end{array}$ & $\begin{array}{l}61 \text { to } 763 \mathrm{~W} \\
17 \text { to } 215 \mathrm{~W} \\
7 \text { to } 87 \mathrm{~W}\end{array}$ & $\begin{array}{l}150 \text { to } 1900 \\
42 \text { to } 540 \\
23 \text { to } 220\end{array}$ & $\begin{array}{l}48 \text { to } 350 \\
27 \text { to } 120 \\
24 \text { to } 65\end{array}$ \\
\hline $60 \mathrm{GHZ}$ & $\begin{array}{l}3 \mathrm{ft} \\
4 \mathrm{ft} \\
5 \mathrm{ft}\end{array}$ & $\begin{array}{l}66 \text { to } 77 \\
63 \text { to } 74 \\
61 \text { to } 72\end{array}$ & $\begin{array}{l}17 \text { to } 217 \mathrm{~W} \\
5 \text { to } 61 \mathrm{~W} \\
2 \text { to } 25 \mathrm{~W}\end{array}$ & $\begin{array}{l}50 \text { to } 560 \\
18 \text { to } 160 \\
10 \text { to } 70\end{array}$ & $\begin{array}{l}25 \text { to } 120 \\
20 \text { to } 50 \\
22 \text { to } 35\end{array}$ \\
\hline
\end{tabular}

TABLE 3. - C-BAND SINGLE Beam CONUS COVERAge REPRESENTATIVE LIHK BUDGeT

\begin{tabular}{|c|c|c|}
\hline Link parameter & $\begin{array}{ll}\text { Uplink, } & d B \\
\left(f_{u p}=6\right. & G H z)\end{array}$ & $\begin{array}{l}\text { Downlink, } \frac{d B}{\left(f_{\text {down }}=4 \mathrm{GHz}\right)}\end{array}$ \\
\hline 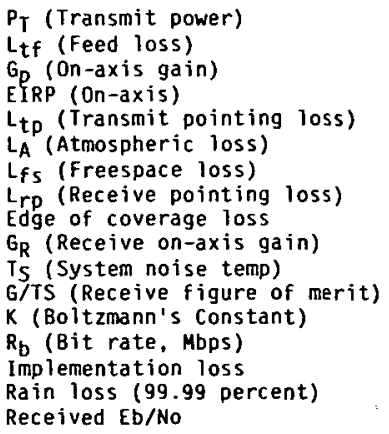 & $\begin{array}{r}27.0(500 \mathrm{~W}) \\
-1.0 \\
53.7(32.8 \mathrm{ft}) \\
79.7 \\
-0.24\left(0.05^{\circ} \text { Error }\right) \\
-0.5\left(5^{\circ} \text { Elevation }\right) \\
-200.3\left(5^{\circ} \text { Elevation }\right) \\
-.005\left(.07^{\circ} \text { Error }\right) \\
-3.0 \\
34.2(5.4 \text { by } 2.3 \mathrm{ft}) \\
+30.0\left(1000^{\circ} \mathrm{K}\right) \\
4.3 \\
-228.6 \\
+77.8(60 \mathrm{Mbps}) \\
-1.5 \\
-3.0 \\
26.3 \mathrm{~dB}\end{array}$ & $\begin{array}{r}7.0(5 \mathrm{w}) \\
-1.0 \\
30.8(5.4 \text { by } 2.3 \mathrm{ft}) \\
35.8 \\
-0.002\left(0.07^{\circ} \text { Error }\right) \\
-0.44\left(5^{\circ} \text { Elevation) }\right. \\
-196.8\left(5^{\circ} \text { Elevation) }\right. \\
-.11\left(.05^{\circ} \text { Error) }\right. \\
-3.0 \\
50.2(32.8 \mathrm{ft}) \\
+24.8\left(300^{\circ} \mathrm{K}\right) \\
25.5 \\
-228.6 \\
+77.8(60 \mathrm{Kbps}) \\
-1.5 \\
-1.0 \\
10.3 \mathrm{~dB}\end{array}$ \\
\hline
\end{tabular}


TABLE 4. - KU-BAND SINGLE BEAM CONUS COVERAGE REPRESENTATIVE LINK BUDGET

\begin{tabular}{|c|c|c|}
\hline Link parameter & $\begin{array}{c}\text { Uplink, } d B \\
\left(f_{\text {up }}=14 \mathrm{GHz}\right)\end{array}$ & $\begin{array}{c}\left.\text { Downlink, } \frac{d B}{\left(f_{\text {down }}=12 \mathrm{GHz}\right.}\right)\end{array}$ \\
\hline 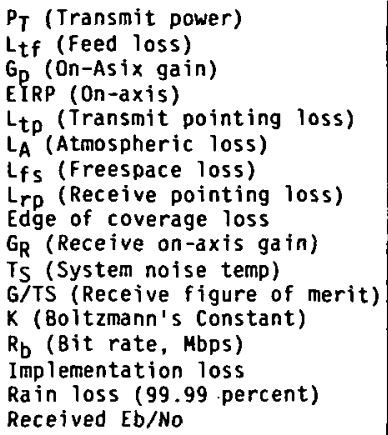 & $\begin{array}{r}23.0(200 \mathrm{~W}) \\
-1.0 \\
55.1(16.4 \mathrm{ft}) \\
77.1 \\
-0.33\left(0.05^{\circ} \text { Error }\right) \\
-0.5\left(10^{\circ} \text { Elevation) }\right. \\
-207.5\left(10^{\circ} \text { Elevation) }\right. \\
-0.0 \\
-3.0 \\
32.0(1.8 \text { by } 0.7 \mathrm{ft}) \\
+30.0(1000 \mathrm{~K}) \\
2.0 \\
-228.6 \\
+79.5(90 \text { Mbps) } \\
-1.5 \\
-4.0 \\
11.3 \mathrm{~dB}\end{array}$ & $\begin{array}{r}13.0(20 \mathrm{~W}) \\
-1.0 \\
30.6(1.8 \text { by } 0.7 \mathrm{ft}) \\
41.7 \\
-0.003\left(0.07^{\circ} \text { Error }\right) \\
-0.35\left(10^{\circ} \text { Elevation }\right) \\
-206.2\left(10^{\circ} \text { Elevation }\right) \\
-0.24 \\
-3.0 \\
53.7(16.4 \mathrm{ft}) \\
+24.8(300 \mathrm{~K}) \\
29.0 \\
-228.6 \\
+79.5(90 \mathrm{Mbps}) \\
-1.5 \\
-1.5 \\
8.0 \mathrm{~dB}\end{array}$ \\
\hline
\end{tabular}

TABLE 5. - COMPARISON OF C-BAND/KU-BAND SINGLE SATELLITE BASELINE AND ISL END-TO-END LINK PERFORMANCE

\begin{tabular}{|c|c|c|c|c|}
\hline & $\begin{array}{l}\text { C-8and } \\
\text { single sat. } \\
\text { baseline }\end{array}$ & $\begin{array}{l}\text { ISL system } \\
\text { (C-Band } \\
\text { up/down links) }\end{array}$ & $\begin{array}{c}\text { Ku-Band } \\
\text { single sat. } \\
\text { baseline }\end{array}$ & $\begin{array}{c}\text { ISL system } \\
\text { (Ku-Band } \\
\text { up/down links) }\end{array}$ \\
\hline $\begin{array}{l}\text { Net Eb/No ( } d B) \\
\text { BER (OPSK uncoded) } \\
\text { BER }(R=7 / 8 \text { code) } \\
\text { BER ( } R=3 / 4 \text { code) } \\
\text { BER (uncoded, IF remod) }\end{array}$ & $\begin{array}{l}10.2 \\
3 \times 10^{-6} \\
<10^{-10} \\
<10^{-10}\end{array}$ & $\begin{array}{l}\quad a_{7} .7 \\
3 \times 10^{-4} \\
10^{-7} \\
10^{-10} \\
2.2 \times 10^{-6}\end{array}$ & $\begin{array}{c}6.3 \\
10^{-3} \\
2 \times 10^{-5} \\
2 \times 10^{-7} \\
-----\end{array}$ & $\begin{array}{c}b_{5} .9 \\
10^{-2} \\
8 \times 10^{-5} \\
10^{-6} \\
2 \times 10^{-4}\end{array}$ \\
\hline
\end{tabular}

a Assumes uplink Eb/No improvement of $4.2 \mathrm{~dB}$ and $11.3 \mathrm{~dB}$ crosslink Eb/No.

bAssumes uplink Eb/No improvement of $4.7 \mathrm{~dB}$ and $11.3 \mathrm{~dB}$ crosslink Eb/No.

TABLE 6. - COMMUNICATIONS PAYLOAD COMPARISON

\begin{tabular}{|l|c|c|c|c|}
\hline & \multicolumn{2}{|c|}{ C-Band } & \multicolumn{2}{c|}{ Ku-Band } \\
\cline { 2 - 5 } & Baseline & ISL & Baseline & ISL \\
\hline Antenna size, ft & 5.4 by 2.3 & 6.6 by 5.0 & 1.8 by 0.7 & 2.2 by 1.6 \\
HPA Power, W & 5.0 & 2.0 & 20.0 & 7.2 \\
Payload power, W & 376 & 150 & 1079 & 396 \\
Payload weight, 1b & 325 & 250 & 557 & 278 \\
ISL weight margin, 1b &..---- & 75 & $-\ldots$ & 279 \\
\hline
\end{tabular}


TABLE 7. - EARTH STATION COMPARISON

\begin{tabular}{|l|c|c|c|c|}
\hline \multirow{2}{*}{} & \multicolumn{2}{|c|}{ C-Band } & \multicolumn{2}{c|}{ KU-Band } \\
\cline { 2 - 5 } & $\begin{array}{c}\text { Baseline/ISL } \\
\text { Scenario 1 }\end{array}$ & $\begin{array}{c}\text { ISL } \\
\text { Scenario 2 }\end{array}$ & $\begin{array}{c}\text { Baseline/ISL } \\
\text { Scenario 1 }\end{array}$ & $\begin{array}{c}\text { ISL } \\
\text { Scenario 2 }\end{array}$ \\
\hline EIRP, dBW & 79.7 & 75.5 & 77.1 & 72.4 \\
G/T, dB/K & 25.5 & 21.3 & 29.0 & 24.3 \\
HPA power, W & 1175.0 & 525.0 & 140.0 & 56.0 \\
Antenna diameter, ft & 21.3 & 19.7 & 19.7 & 18.0 \\
Noise temp, K & 125.3 & 281.2 & 430.0 & 1050.0 \\
\hline
\end{tabular}

TABLE 8. - SYSTEM COSTS

\begin{tabular}{|c|c|c|c|c|c|c|}
\hline & \multicolumn{3}{|c|}{ C-Band } & \multicolumn{3}{|c|}{ Ku-Band } \\
\hline & $\begin{array}{l}\text { Baseline } \\
\text { Scenario }\end{array}$ & $\begin{array}{c}\text { ISL } \\
\text { Scenario } 1\end{array}$ & $\begin{array}{c}\text { ISL } \\
\text { Scenario } 2\end{array}$ & $\begin{array}{l}\text { Baseline } \\
\text { Scenario }\end{array}$ & $\begin{array}{c}\text { ISL } \\
\text { Scenario } 1\end{array}$ & $\begin{array}{l}\text { ISL } \\
\text { Scenario } 2\end{array}$ \\
\hline $\begin{array}{l}\text { First unit, } \$ M \\
\text { Second unit, } \$ M \\
\text { Nonrecurring, } \$ M \\
\text { Space segment cost, } \$ M \\
\text { E/S RF cost, } \$ K\end{array}$ & $\begin{array}{r}38 \\
34 \\
76 \\
148 \\
67\end{array}$ & $\begin{array}{r}32 \\
29 \\
64 \\
\mathbf{a} 125 \\
67\end{array}$ & $\begin{array}{r}39 \\
35 \\
78 \\
\frac{78}{152} \\
47.5\end{array}$ & $\begin{array}{c}57 \\
51 \\
\frac{114}{222} \\
53.5\end{array}$ & $\begin{array}{r}36 \\
32 \\
72 \\
9140 \\
53.5\end{array}$ & $\begin{array}{r}58 \\
52 \\
116 \\
a 226 \\
37\end{array}$ \\
\hline
\end{tabular}

aDoes not include $15 L$. 


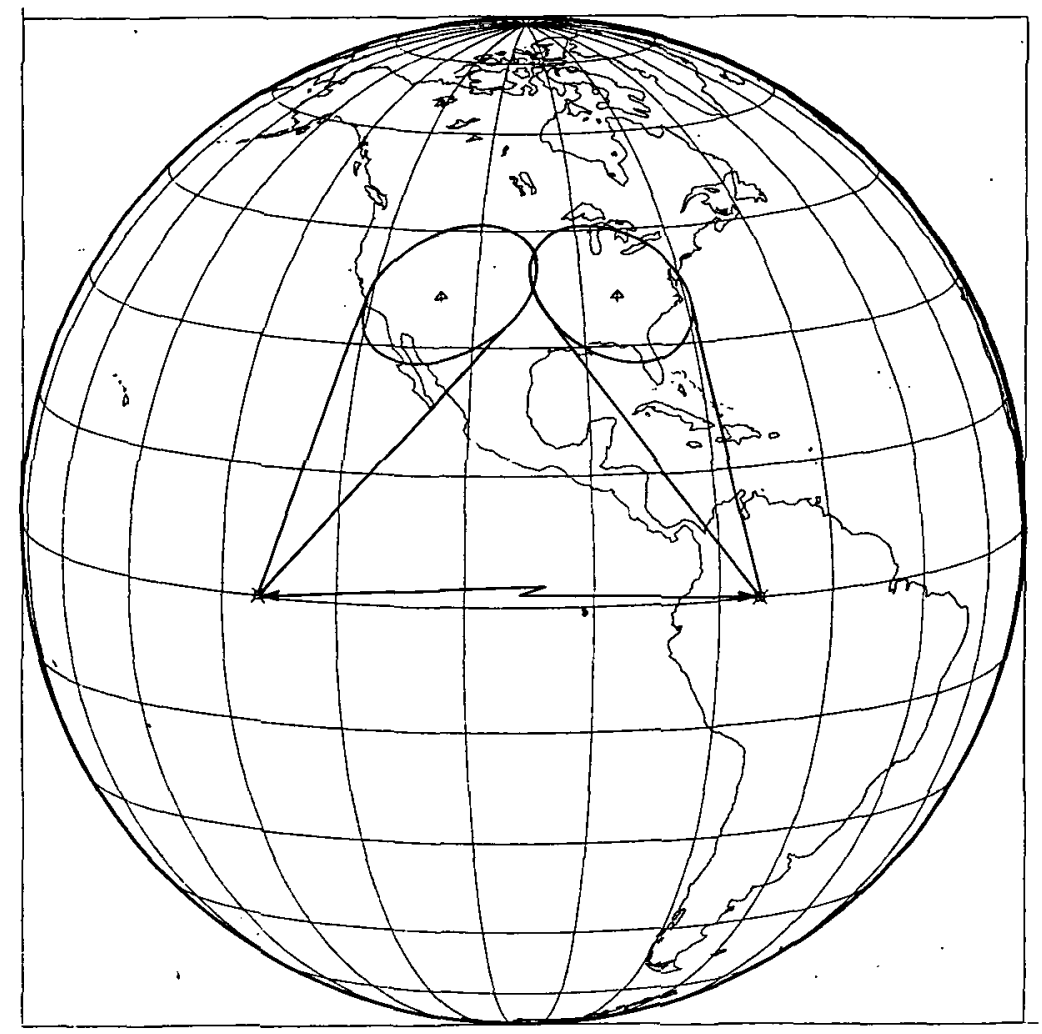

Figure 1. Two-satellite ISL configuration. 


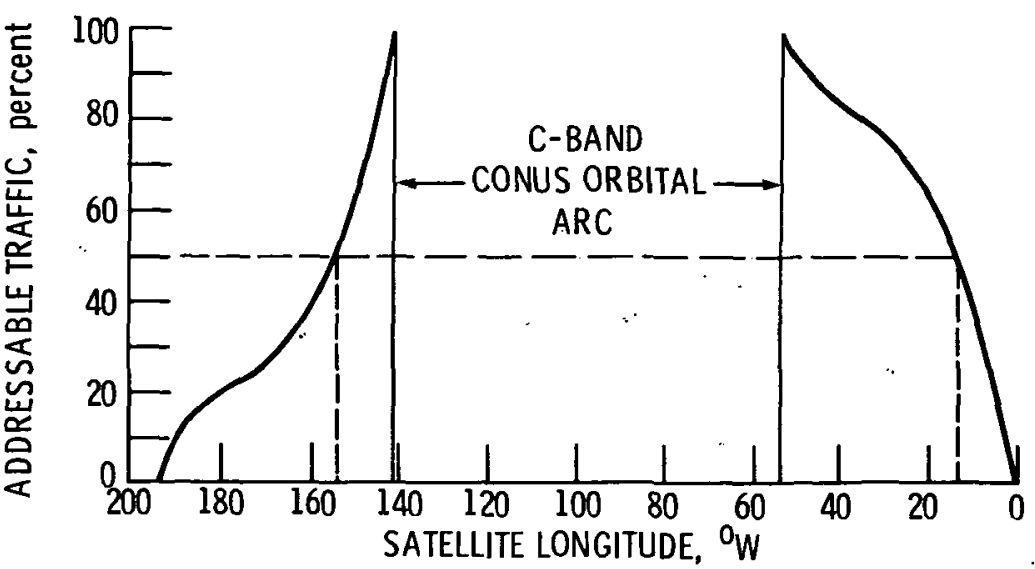

Figure 2. - Amount of satellite addressable traffic accessible from C-band orbit locations.

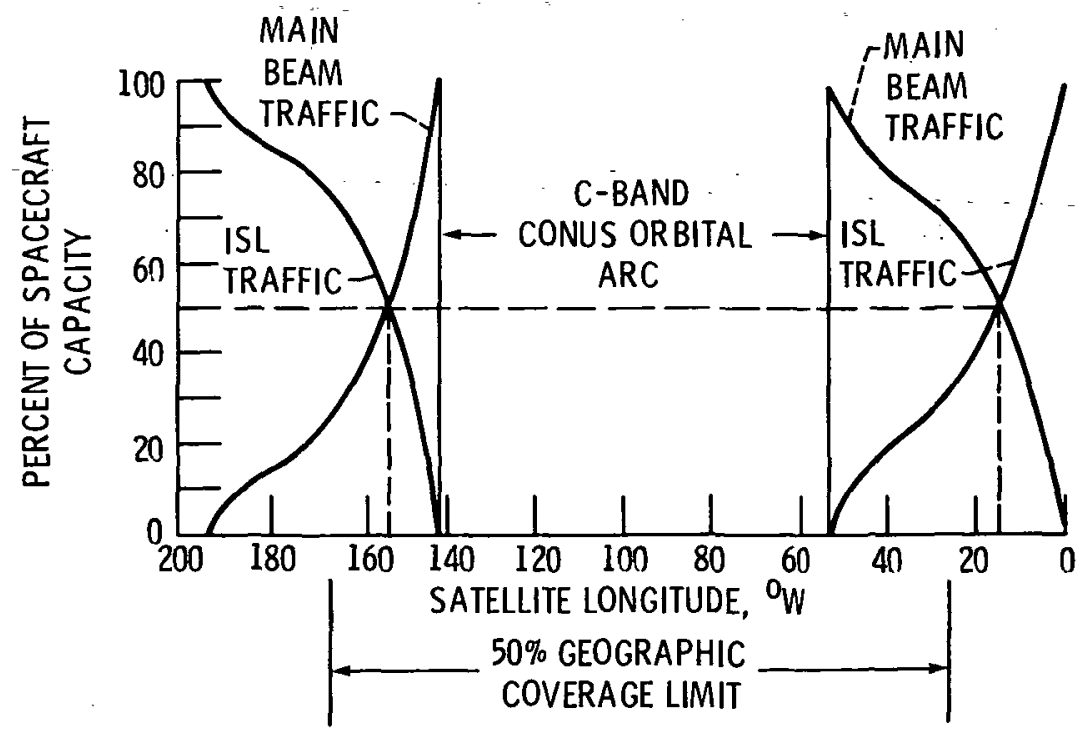

Figure 3. - ISL, mainbeam traffic routing from C-band orbit locations. 


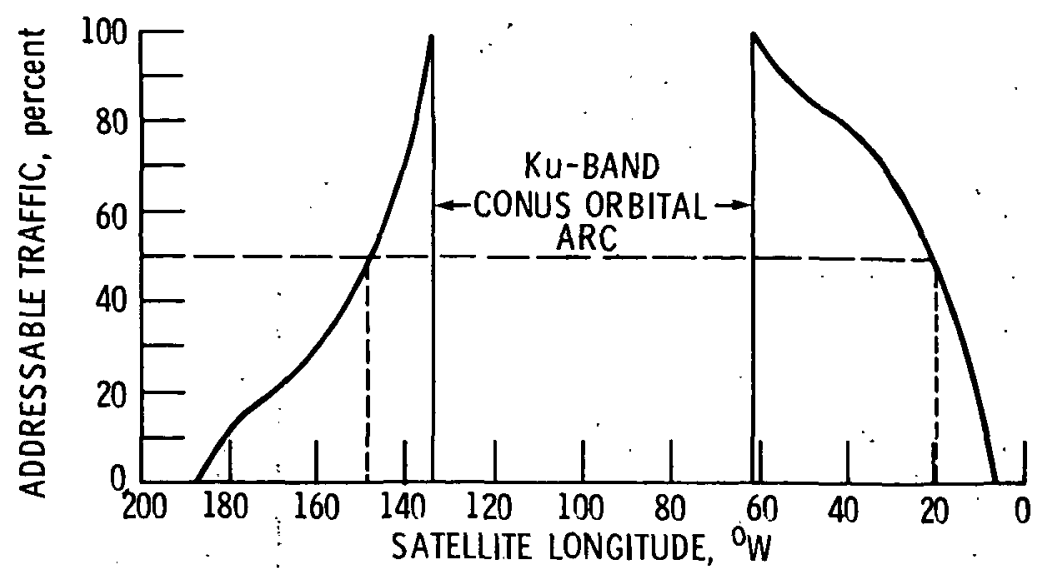

Figure 4. - Amount of satellite addressable traffic accessible from Ku-band orbit locations.

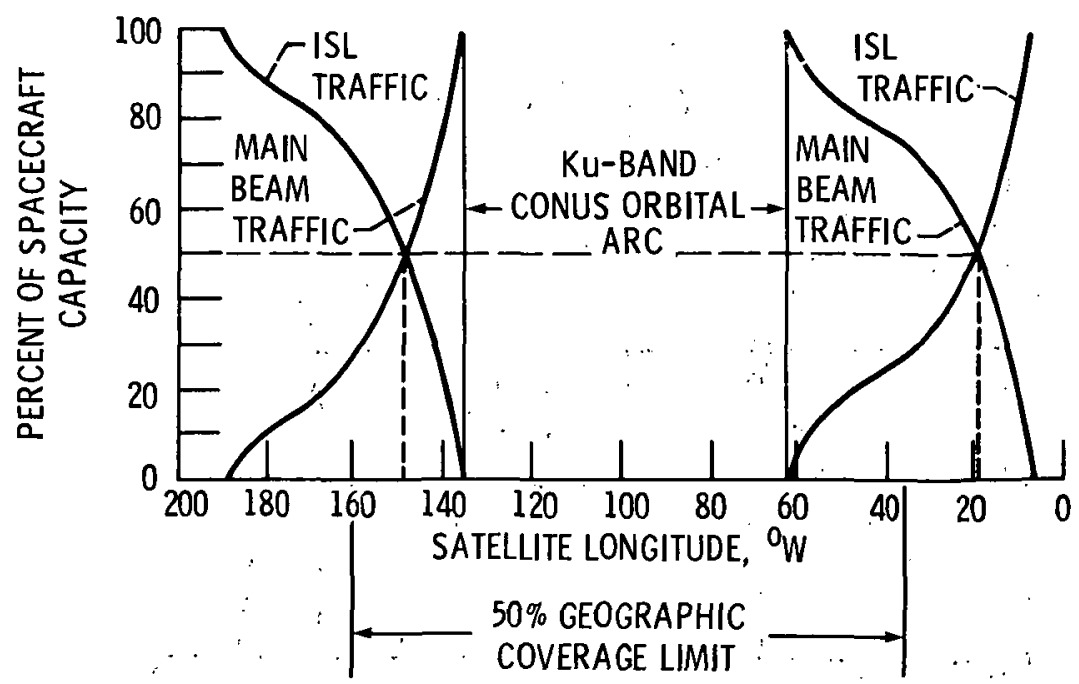

Figure 5. - ISL, mainbeam traffic routing from Ku-band orbit locations. 


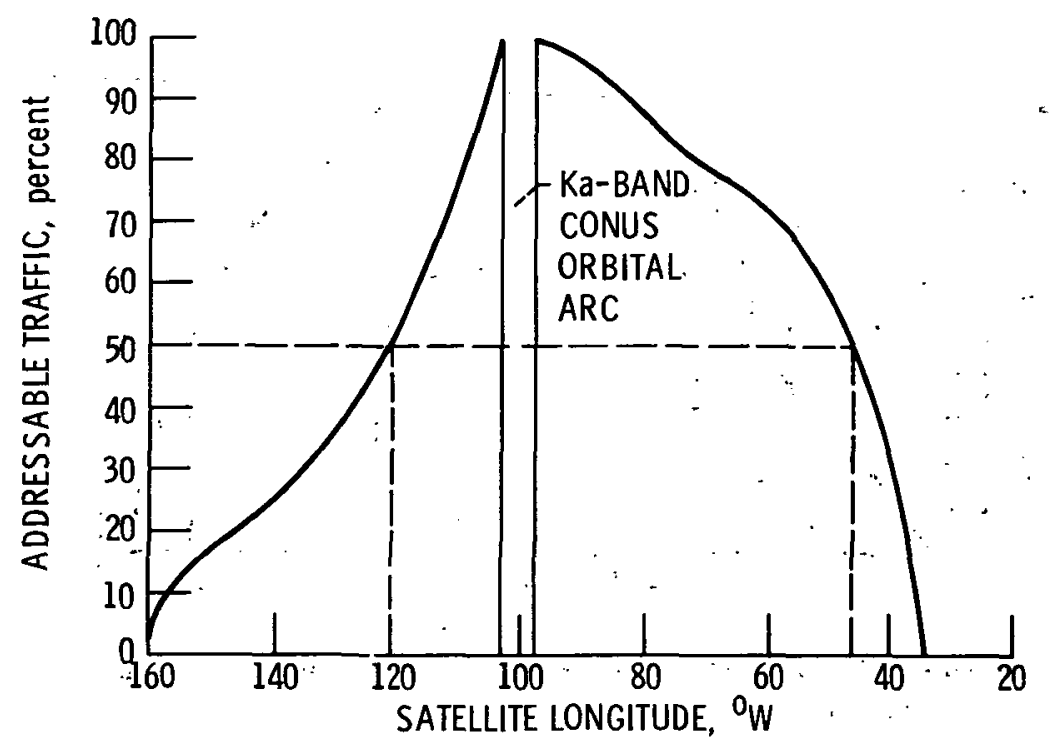

Figure 6. - Amount of satellite addressable traffic accessible from Ka-band orbit locations.

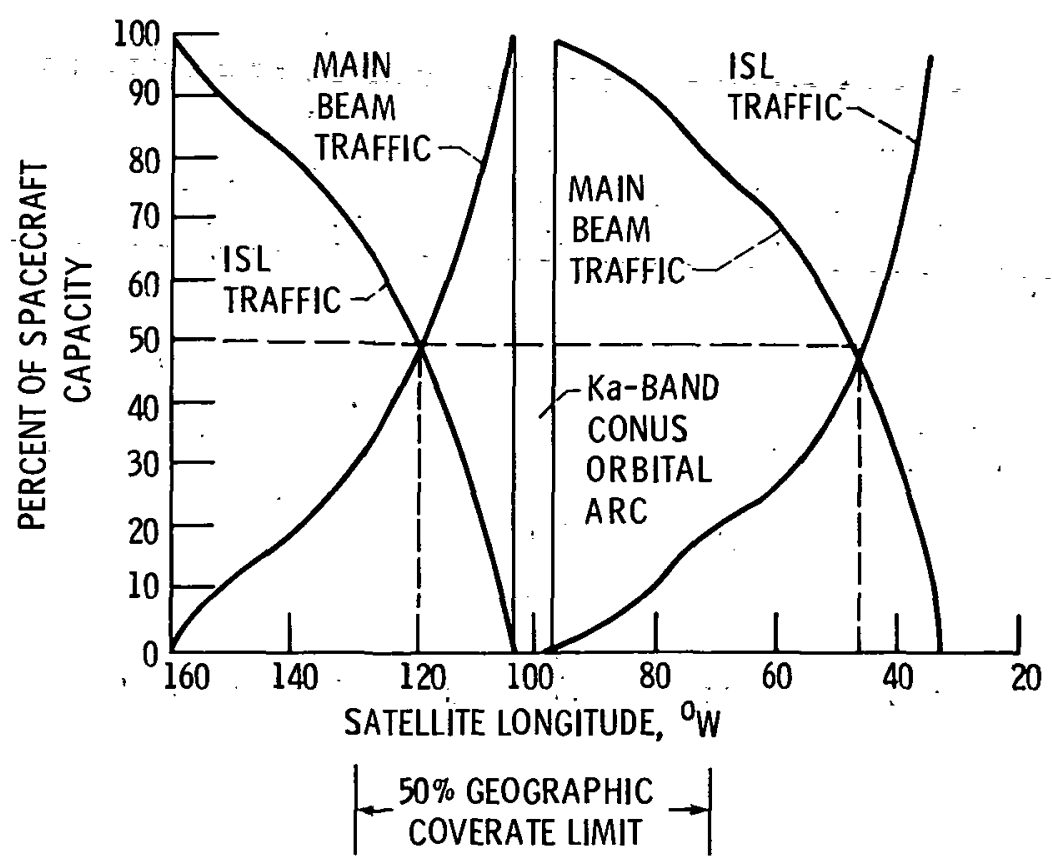

Figure 7. - ISL, mainbeam traffic routing from Ka-band orbit locations. 


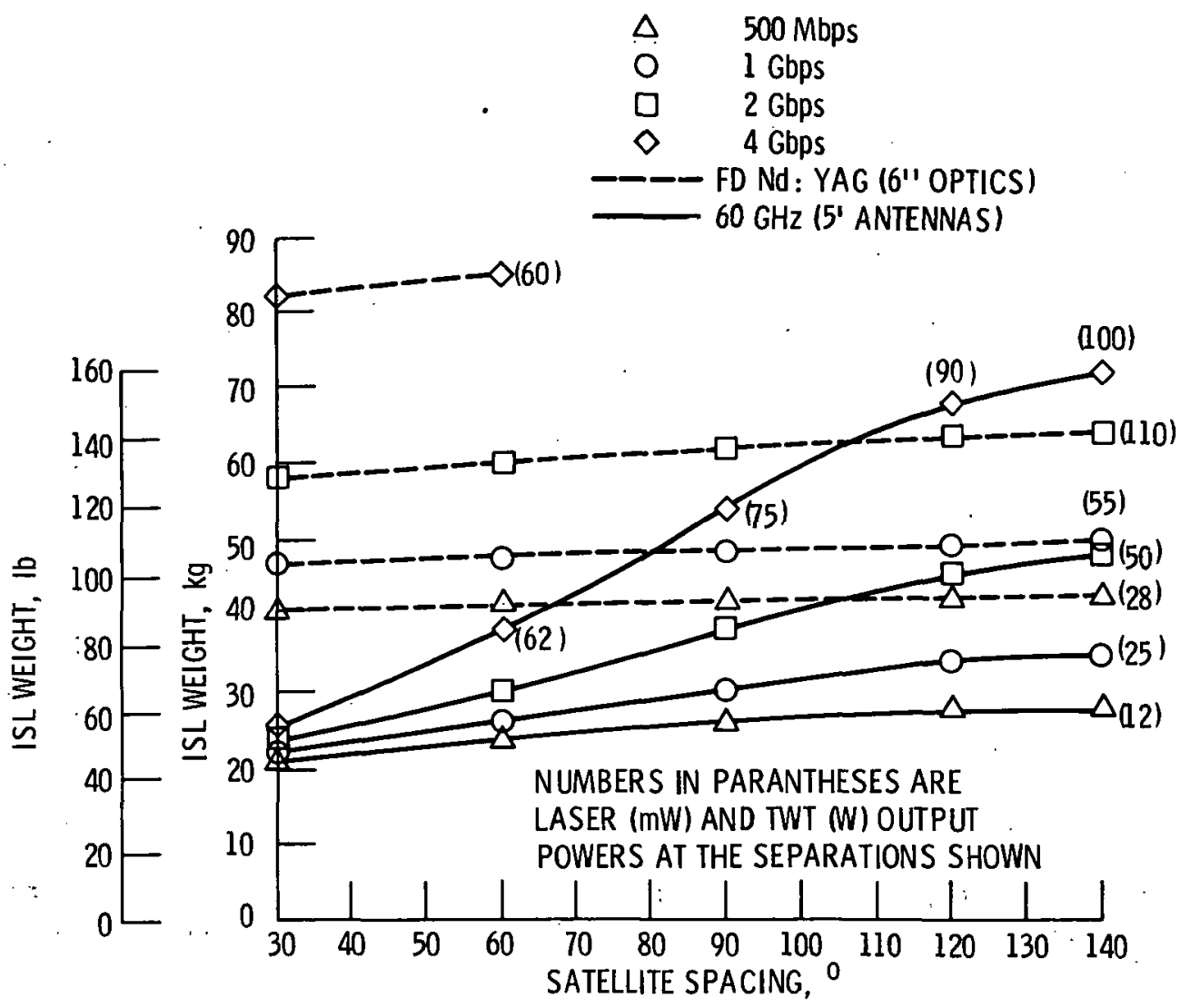

Figure 8. ISL weight versus $\theta\left(10^{-7}\right.$ BER).

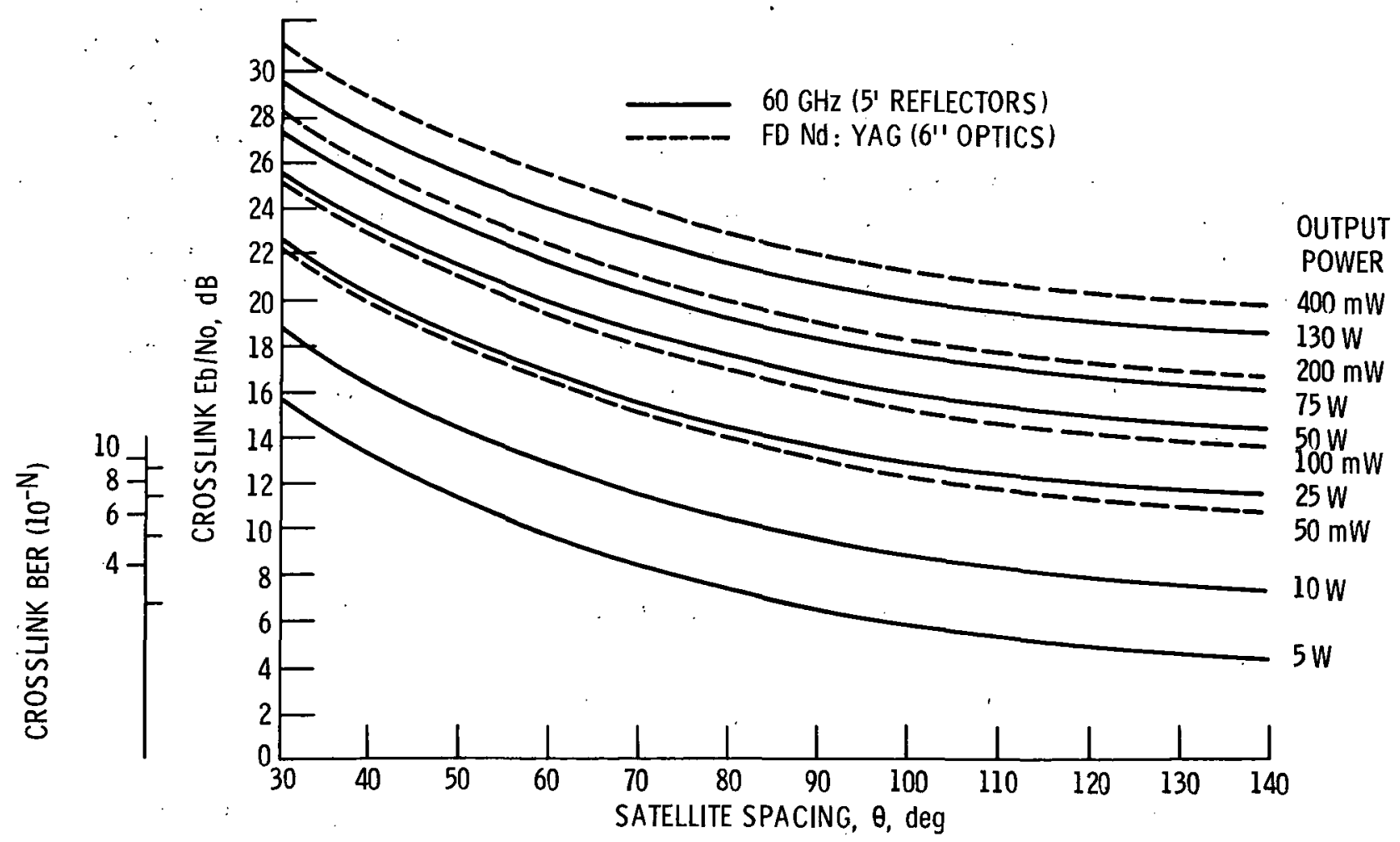

Figure 9. - ISL BER and Eb/No versus $\theta, 1$ Gbps crosslink. 


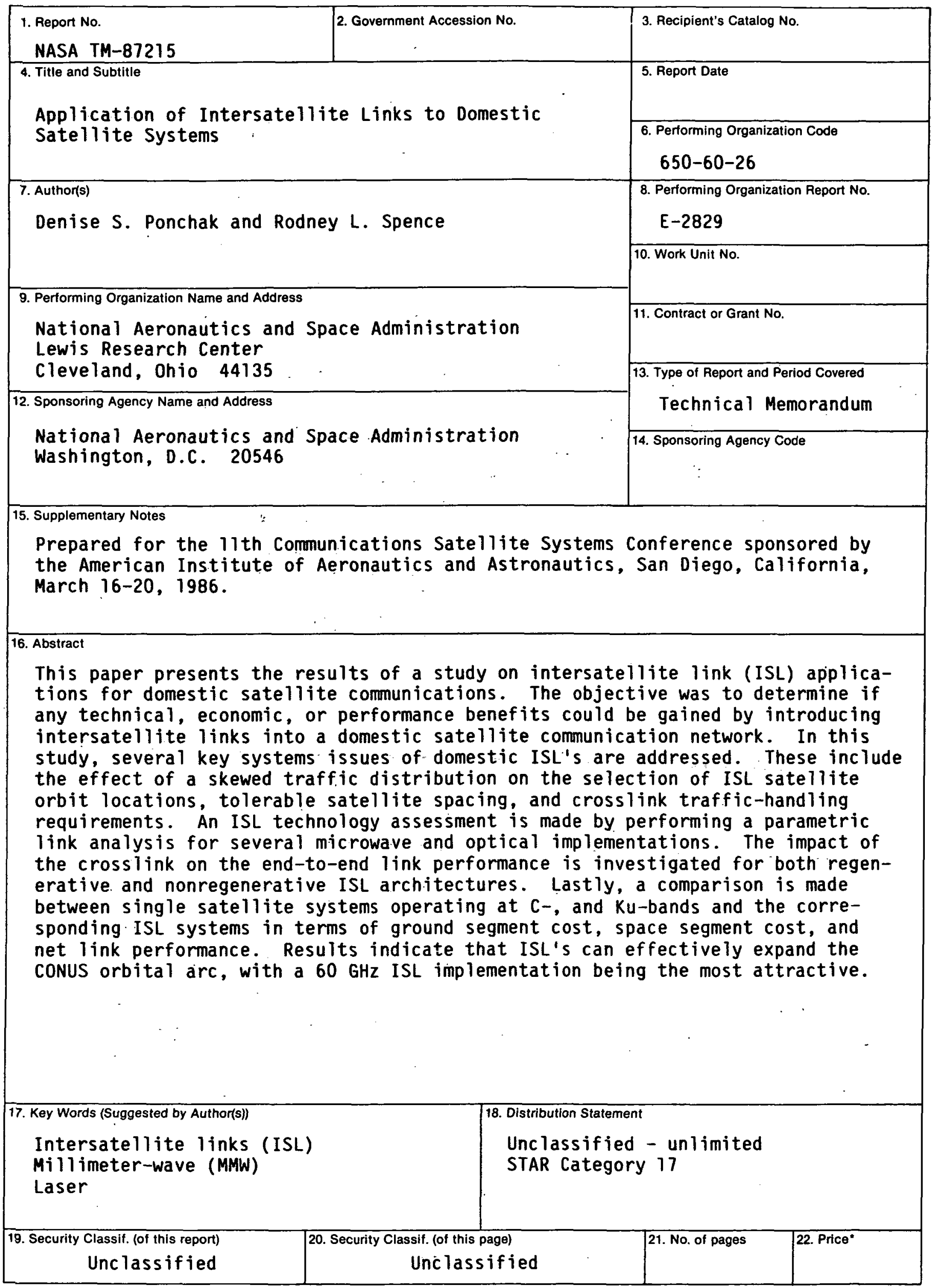


National Aeronautics and Space Administration

Lewis Research Center

Cleveland. Ohio 44135

Official Business

Penalty for Private Use $\$ 300$
SECOND CLASS MAIL

ADDRESS CORRECTION REQUESTED

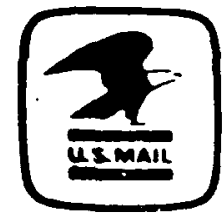

Postage and Fees Paid National Aeronautics and Space Administration NASA-451 